\title{
ARAŞTIRMA/RESEARCH \\ Üniversite öğrencilerinde huzursuz bacaklar sendromu sıklığı ve yaşam kalitesi ile ilişkisi
}

The frequency of restless legs syndrome and relationship with quality of life among university students

\author{
Seden Demirci ${ }^{1}$, Ahmet Taha Şahin ${ }^{2}$ \\ ${ }^{1}$ Süleyman Demirel Üniversitesi Tip Fakültesi, Nöroloji Anabilim Dalı, Isparta, Turkey \\ ${ }^{2}$ Süleyman Demirel Üniversitesi Tip Fakültesi, Isparta, Turkey
}

Cukurova Medical Journal 2016;41(3):423-428.

\begin{abstract}
Purpose: The aim of this study was to investigate the prevalence of restless legs syndrome, the severity of symptoms and the relationship between restless legs syndrome and quality of life among university students.

Material and Methods: The participant students were asked the four questions essential for a diagnosis of restless legs syndrome and the students who answered 'yes' to all four questions were evaluated according to International Restless Legs Syndrome Study Group (IRLSSG) diagnostic criteria by an experienced neurologist and diagnosis was made. The severity of restless legs syndrome was investigated using IRLSSG rating scale and the quality of life was assessed by the Short form-36 (SF36).

Results: A total of 447 students-238 female (53.2\%) and 209 male (46.8\%)-were included in this study. Restless legs syndrome was diagnosed in $7.6 \%$ of the students. Mean restless legs syndrome severity was $13.1 \pm 5.44$. There were significantly lower levels of the physical and mental component of SF-36 scores in participants with restless legs syndrome compared to in those without restless legs syndrome. There was a negative correlation between the severity of restless legs syndrome and physical component of SF-36.
\end{abstract}

Conclusion: Evaluation of university students in terms of restless legs syndrome, which is not well known in the population and adversely affect the quality of life, may be helpful.

Key words: Restless legs syndrome, quality of life, university students
Öz

Amaç: Bu çalışmanın amacı üniversite öğrencileri arasında huzursuz bacaklar sendromu sıklığını, semptom şiddetini ve huzursuz bacaklar sendromunun yașam kalitesi ile ilişkisini araştırmaktır.

Gereç ve Yöntem: Katılımc1 öğrencilere huzursuz bacaklar sendromu tanı kriterlerini içeren dört soru soruldu ve bu dört soruya 'evet' cevabı veren öğrenciler Nöroloji uzmanı tarafindan Uluslararası Huzursuz Bacaklar Sendromu Çalışma Grubu (UHBÇG) kriterlerine göre değerlendirildi ve huzursuz bacaklar sendromu tanısı konuldu. Huzursuz bacaklar sendromu bulunan öğrencilere hastalık şiddetini ölçmek için UHBÇG Şiddet Skalası uygulandı ve yaşam kalitesini değerlendirmek için tüm katılımcilara Kısa form-36 (KF-36) uygulandı.

Bulgular: Çalışmaya 238'i $(\% 53,2)$ kız, 209'u $(\% 46,8)$ erkek olmak üzere toplam 447 öğrenci katıldı. Öğrencilerin \%7.6'sinda huzursuz bacaklar sendromu saptandi. Huzursuz bacaklar sendromu şiddeti ortalama 13,1 $\pm 5,44$ olarak belirlendi. Huzursuz bacaklar sendromu bulunan öğrencilerde KF-36 fizik ve mental bölümü skorları anlamlı düzeyde düşük saptandı. Huzursuz bacaklar sendromu S şiddet düzeyi ile KF-36 fizik bölümü skorları arasında anlamlı negatif ilișki saptandı.

Sonuç: Üniversite öğrencilerinin halen toplumda yeterince bilinmeyen ve yaşam kalitesini olumsuz etkileyebilen huzursuz bacaklar sendromu açisından değerlendirilmesinin faydalı olacağını düşünmekteyiz.

Anahtar kelimeler: Huzursuz bacaklar sendromu, yaşam kalitesi, üniversite öğrencileri

Yazıșma Adresi/Address for Correspondence: Dr. Seden Demirci, Süleyman Demirel Üniversitesi Tip Fakültesi, Nöroloji Anabilim Dalı, Isparta, Turkey, E-mail: sdndemirci@yahoo.com.tr

Geliş tarihi/Received: 03.11.2015 Kabul tarihi/Accepted: 18.12.2015 


\section{GİRİ̧̧}

Huzursuz bacaklar sendromu (HBS) ya da WillisEkbom hastalığı, Özellikle akşamları, sıklıkla nahoş ve rahatsiz edici hisler sonrasinda, bacakları dayanılamaz şekilde hareket ettirme ihtiyacı ve hareket ettirmeyle geçici rahatlamanın olduğu sensorimotor nörolojik bir hastalıktır ${ }^{1}$. Patofizyolojisi henüz kesin olarak ortaya konulamamasına rağmen, santral sinir sisteminde demir depolarında azalma, dopaminerjik düzensizlikler ve genetik faktörler patojenezde en önemli etkenler olarak bilinmektedir ${ }^{2}$.

Ailesel ve idiyopatik olarak ortaya çıan formu primer HBS olup, en sık görülen formudur ve bu formda hastalık başlangıç yaşı erken olup genellikle 20 yaşın altındadır. Sekonder form ise gebelik, demir eksikliği anemisi, böbrek yetersizliği, periferik nöropati, spinoserebellar ataksi, diabetes mellitus, hipotiroidizm, romatoid artrit gibi hastaliklarla ve antidepresanlar, antiepileptikler, dopamin reseptör blokörleri gibi ilaçlarla ilişkili olarak görülebilir ${ }^{3}$.

Epidemiyolojik çalışmalara göre, HBS prevalans1 \%2 ile $\% 15$ arasında değişmektedir ${ }^{3-5}$. Yapılan çalışmalarda 8-11 yaş arasında $\% 1,9,12-17$ yaş arasinda $\% 2,18-20$ yaş grubunda ise prevalansı $\% 9$ ile $\% 15$ arasında bildirilmiştir ${ }^{6-11}$. HBS tanısı esasen klinik öyküye dayanmaktadır. Hastaların çoğu şikayetlerini ifade ederken güçlük yaşarlar. Belirtilerin tanımlanmasında; hareket ihtiyacı, karıncalanma, sızlama, huzursuzluk, kramp, bacak üzerinde bir şey sürünüyor hissi, bacaklarda yanma, çekilme, ağrı-acıma, elektrik hissi, gerilme, rahatsızlık hissi ve kaşınma gibi ifadeler kullanırlar. Semptomların karmaşıklığı ve güç tanımlanır olması tanıyı zorlaştırmaktadır.

Uluslararası Huzursuz Bacaklar Sendromu Çalışma Grubu (UHBSÇG) tarafindan standardize kriterler önerilmiştir ${ }^{12}$. Semptom şiddetleri değişkenlik gösterdiği için olduğundan daha az tanı konulan bir hastalıktır. İleri yaş ve kadın cinsiyet HBS için risk faktörleridir ${ }^{1}$.

HBS, huzursuzluk, ağrı, yorgunluk, dinlenememe, uyku bozuklukları ve bunların sonucunda ortaya çıkan depresyon, anksiyete gibi birçok yönüyle hastaların yaşam kalitesini olumsuz olarak etkilemektedir ${ }^{13}$. Bu çalışmanın amacı, genç yaş grubu olan üniversite öğrencileri arasında HBS sıklığını, semptom şiddetini ve HBS'nin yaşam kalitesi ile ilișkisini araştırmaktır.

\section{GEREÇ VE YÖNTEM}

\section{Katılımcilar}

Araştırma için Süleyman Demirel Üniversitesinde eğitim gören 500 öğrenciye ulaşılması planlanmıştır. Diabetes mellitus, demir eksikliği anemisi, romatoid artrit, kronik sistemik hastalık, kronik nörolojik hastalık, alkol kullanım ve düzenli ilaç kulanım öyküsü olanlar çalışmaya dahil edilmemiştir. Çalışmamız 18 kişi dışlama ölçütlerine uymaları, 8 kişi çalışmaya katılmayı kabul etmemeleri, 27 kişi de çalışma ölçeklerini eksik doldurmaları nedeniyle, 238'i kız, 209'u erkek toplam 447 katılımc1 ile gerçekleştirilmiştir. Tüm katılımcılardan sosyodemografik veriler sosyodemografik veri formu ile alınmıştır. HBS bulunan katılımcıların benzer şikayetlerinin 1 . derece akrabalarında da mevcut olup olmadığını içeren HBS ile ilgili veriler Nöroloji uzmanı tarafından kaydedilmiştir. Çalışma Süleyman Demirel Üniversitesi Tip Fakültesi etik kurulu tarafindan onaylanmıştır. Tüm katılımcılardan yazılı onam alınmıştır.

\section{HBS Tanıs1}

HBS tanısı için daha önce tanımlanan UHBSÇG temel tanı kriterleri başlığında belirtilen 4 standart tarama sorusu soruldu ${ }^{1}$.

1. Bacaklarınızda ağrı, sızı, ürperti gibi hoş olmayan, rahatsızlık veren ve bacaklarınızı hareket ettirmeye zorlayan bir his oluyor mu?

2. Bu şikayetler oturma ya da yatma gibi hareketsizlik ya da dinlenme dönemlerinde mi başlıyor ya da artıyor?

3. Bu şikayetler bacağınızı yürüme veya esnetme, germe gibi hareketlerle kısmen veya tamamen geçiyor mu?

4. Bu şikayetler gündüz saatlerine göre akşam ve geceleyin daha $\mathrm{m} 1$ şiddetli oluyor?

Cevapların HBS tanı kriterlerini karşılayıp karşılamadığını değerlendirmek ve HBS'yi taklit eden durumları dışlamak amaciyla 4 soruya da 'evet' cevab1 veren bireylere Nöroloji uzmanı tarafindan klinik görüşme ve nörolojik muayene yapılarak HBS tanisı konuldu.

\section{HBS Şiddeti}

HBS olduğu kabul edilen öğrencilere hastalık şiddetini ölçmek için UHBSÇG Şiddet Skalası uyguland $1^{14}$. Bu skala toplam 10 sorudan 
oluşmaktadır. Her bir sorudaki HBS şiddet değerleri; yok (0 puan), hafif (1 puan), orta ( 2 puan), şiddetli (3 puan) ve çok şiddetli (4 puan) olarak derecelendirilir. Böylece toplamda 0-40 arasında değişen bir skor elde edilir. Toplam skora göre, 0-10 puan hafif, 1120 puan orta, 21-30 puan şiddetli, 31-40 puan çok şiddetli HBS olarak kabul edilir.

\section{Yaşam Kalitesi}

Yaşam kalitesini değerlendirmek için tüm katılımcilara Kisa form-36 (KF-36) anket formu uyguland. Ware ve Sherbourne tarafindan 1989 yılında geliştirilmiş olan KF-36, klinik uygulama ve araştırmalarda yaşam kalitesini ölçmede kullanılan en yaygın jenerik ölçütlerden biridir ${ }^{15}$. Otuzaltı ifadeden oluşan ölçek fiziksel fonksiyon, fiziksel ve emosyonel sorunlara bağlı rol kisitlamaları, sosyal fonksiyon, mental sağlık, enerji/canlılık, ağr1 ve sağlığın genel olarak algılanması gibi sağlığın 8 boyutunu incelemektedir ve fiziksel ve mental sağlık olmak üzere 2 ana başlık içerir.

Her bir alt ölçek en düşük puandan en yüksek puana kadar 0 ile 100 arası değissen değerler alır ve puan yükseldikçe sağlıkla ilişkili yaşam kalitesi artar. Ölçek kişinin kendisini değerlendirme ölçeğidir. Ölçeğin en belirgin avantajları, hasta tarafindan çok kısa sürede doldurulabilmesi, özürlülükteki küçük değişimleri saptamada duyarlı olması ve sağlık durumunun olumsuz olduğu kadar olumlu yönlerini de değerlendirebilmesidir ${ }^{16}$. KF-36'nın Türkçe'ye uyarlanması Koçyiğit ve ark. tarafindan yapılmıştır'17.

\section{İstatistiksel analiz}

İstatistiksel analiz SPSS 15,0 paket programı ile yapılmıştır. Verilerin normallik analizleri Kolmogorov-Smirnov uyum iyiliği testi ile değerlendirilmiştir. İkili grup karşılaştırmalarında normal dağılıma uygun olan veriler için t-testi, uygun olmayanlar için Mann-Whitney U testi kullanılmıştır. Kategorik verilerde grup karşılaştırmaları ki kare testi ile yapılmıştır. Parametreler arası ilişkilerin değerlendirilmesinde Pearson ya da Spearmen korelasyon analizi kullanılmıştır. Değerlendirmelerde anlamlılık düzeyi $\mathrm{p}<0.05$ olarak kabul edilmiştir.

\section{BULGULAR}

Çalışmaya 447 öğrenci alındı. Öğrencilerin 238’i
(\%53.2) kız, 209'u (\%46.8) erkek idi. Yaş ortalaması $20.3 \pm 1.76$ olup, k1zlarda 19.9 \pm 1.47 , erkeklerde $20.8 \pm 1.91$ idi. Öğrencilerin sosyodemografik ve klinik bilgileri Tablo 1'de gösterilmiştir. Öğrencilerin \%7.6'sinda ( $\mathrm{n}=34)$ HBS tespit edildi ve bu öğrencilerin hiçbirisinde daha önceden konulmuş HBS tanısı mevcut değildi.

HBS oranı kızlarda \%9.2 ( $\mathrm{n}=22)$, erkeklerde $\% 5.7$ $(n=12)$ olarak bulundu $(\mathrm{p}=0,, 16)$. HBS saptanan ve saptanmayan öğrenciler yaş bakımından benzer olarak bulundu $(p=0.40)$. HBS saptanan öğrencilerde HBS şiddet düzeyi değerlendirildiğinde 14 (\%41.2) öğrencide hafif, 18 (\%52.9) öğrencide orta ve 2 (\%5.9) öğrencide şiddetli olarak değerlendirildi. HBS şiddeti ortalama 13.1 \pm 5.44 olarak belirlendi. Kız ve erkek öğrenciler arasında şiddet açısından farklılık saptanmadı $(p=0.48)$. Aile öyküsü olan HBS'li katılımcıların ortalama HBS şiddeti $17.1 \pm 5.02$, olmayanların ise $9.61 \pm 2.56$ olarak bulundu $(\mathrm{p}<0.001)$. HBS siklığ1, HBS saptanan öğrencilerin 11'inde (\%32.4) haftada 1 veya daha az, 20'sinde (\%58.8) haftada 2-3 gün, 2'sinde (\%5.9) haftada 4-5 gün, 1'inde (\%2.9) haftada 6-7 gün olarak bulundu. HBS saptanan 34 kişinin 16'sinde (\%47.1) aile öyküsü mevcuttu.

Tüm öğrencilerin ortalama KF-36 fiziksel alt ölçeği

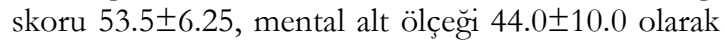
bulundu. HBS bulunan ve bulunmayan öğrencilerin KF-36 skalası alt ölçekleri sayısal ortalamaları karşılaştırıldığında; HBS bulunan öğrencilerde fiziksel ve mental alt ölçek sayısal ortalamaları HBS tanısı olmayan öğrencilere göre daha düşüktü $(\mathrm{p}<$ 0.001, $\mathrm{p}=0.003$, sirasiyla).

HBS bulunan ve bulunmayan öğrencilerin yaşam kalitesinin karşılaştırılması Tablo 2'de gösterilmiştir. HBS sıklı̆̆ına göre yaşam kalitesinin değerlendirilmesi ise Tablo 3'te belirtilmiştir. Aile öyküsü olan HBS'li katılımcıların ortalama KF-36 fiziksel alt ölçeği puanı 46.5 \pm 7.86 , aile öyküsü olmayanların ise $52.1 \pm 6.71$ saptand $1(p=0.02)$. Aile öyküsü olan HBS'li katılımcıların ortalama KF-36 mental alt ölçeği puanı ise $36.8 \pm 9.87$, olmayanların $41.3 \pm 12.4$ olarak $(p=0.22)$.

HBS şiddet düzeyi ile KF-36 fiziksel bölümü skorlar1 arasında anlamlı negatif ilişki saptandı $(r=-0.434$, $\mathrm{p}=0.01)$. HBS şiddet düzeyi ile KF-36 mental bölümü skorları ve yaş arasında anlamlı ilişki saptanmadi $(\mathrm{p}>0.05)$. 
Tablo 1. Öğrencilerin sosyodemografik ve klinik verileri $(n=447)$

\begin{tabular}{|l|c|}
\hline Yaş, yll ort \pm SS & $20.3 \pm 1.76$ \\
\hline Cinsiyet $(\mathrm{K} / \mathrm{E})$ & $238 / 209$ \\
\hline HBS varlı̆̆1, $\mathrm{n}(\%)$ & $34(\% 7.6)$ \\
\hline HBS şiddeti, ort \pm SS & $13.1 \pm 5.44$ \\
\hline HBS aile öyküsü, $\mathrm{n}(\%)$ & $16(\% 47.1)$ \\
\hline KF-36 Fiziksel, ort $\pm S S$ & $53.5 \pm 6.25$ \\
\hline KF-36 Mental, ort $\pm S S$ & $44.0 \pm 10.0$ \\
\hline
\end{tabular}

HBS: Huzursuz bacaklar sendromu, K: k1z, E: erkek, KF-36: kısa form-36, SS: standart sapma

Tablo 2. HBS bulunan ve bulunmayan öğrencilerin yaşam kalitesi bakımından karşılaştırılması

\begin{tabular}{|l|c|c|c|}
\hline & $\begin{array}{c}\text { HBS bulunan bireyler } \\
\mathbf{n}=\mathbf{3 4}\end{array}$ & $\begin{array}{c}\text { HBS bulunmayan bireyler } \\
\mathbf{n}=\mathbf{4 1 3}\end{array}$ & $\mathbf{p}$ \\
\hline KF-36 Fiziksel, ort \pm SS & $49.5 \pm 7.71$ & $53.9 \pm 6.00$ & $<0.001$ \\
\hline KF-36 Mental, ort \pm SS & $39.2 \pm 11.3$ & $44.4 \pm 9.79$ & 0.003 \\
\hline
\end{tabular}

HBS: Huzursuz bacaklar sendromu, KF-36: k1sa form-36, SS: standart sapma

Tablo 3. HBS sıklığına göre yaşam kalitesinin değerlendirilmesi

\begin{tabular}{|l|c|c|}
\hline Siklık & KF-36 Fizik & KF-36 Mental \\
\hline Haftada 1 veya daha az $(\mathrm{n}=11)$ & $52.4 \pm 7.02$ & $42.4 \pm 8.24$ \\
\hline Haftada 2-3 gün $(\mathrm{n}=20)$ & $48.8 \pm 7.18$ & $38.2 \pm 12.6$ \\
\hline Haftada 4-5 gün $(\mathrm{n}=2)$ & $49.2 \pm 1.06$ & $40.2 \pm 1.06$ \\
\hline Haftada 6-7 gün $(\mathrm{n}=1)$ & 30.0 & 20.0 \\
\hline
\end{tabular}

HBS: Huzursuz bacaklar sendromu, KF-36: kısa form-36

\section{TARTIŞMA}

Bu çalışma sonuçları bize üniversite öğrencilerinin \%7,6'sında HBS saptandığını ve bu öğrencilerin $\% 94,1$ 'inde semptomlarin hafif ve orta düzey olduğunu, HBS bulunan ögrencilerin fiziksel ve mental yaşam kalitesinin bulunmayanlara göre anlamlı olarak daha kötü olduğunu ve ayrıca, HBS şiddet düzeyi ile fiziksel yaşam kalitesi arasında anlamlı negatif ilişkinin varlığını göstermektedir.

Yapılan epidemiyolojik çalışmalara göre toplumda HBS görülme s1klığ1 \%2-15 olarak bildirilmektedir ${ }^{3-5}$. Erişkin popülasyonunda yapılan bir çalışmada HBS s1klığ $\% 7,2$; semptom siklığ1 haftada en az 2 olan bireylerde ise $\% 2,7$ olarak belirlenmiştir' ${ }^{9}$. Türkiye'de ise toplum çalışmalarında sıklık \%3,19-9,71 olarak bildirilmiştir ${ }^{4,18,19}$. HBS yaşlılık döneminde sıklı̆̆1 artan bir hastalık olarak biliniyor olsa da, çocuklarda da nadir değildir. Çocukluk ve adölasan döneminde ise prevalansın $\% 2$ civarında olduğu bildirilmiştir ${ }^{11}$. Minar ve arkadaşlarının 300 üniversite öğrencisinde yaptıkları bir çalışmada öğrencilerin \% 9'unda HBS tespit etmişler ve bu öğrencilerin \%94'ünden fazlasinda semptomlarin hafif-orta, sadece \%2'sinin orta veya şiddetli olduğunu bildirmişlerdir ${ }^{20}$. Ülkemizde tıp fakültesi öğrencileri arasında yapılmış olan bir çalışmada HBS sıklığı \%2,3 olarak bulunmuştur ve HBS şiddeti hafif ve orta düzey olarak bildirilmiştir ${ }^{21}$. Ordu Üniversitesi öğrencileri arasında yapılan bir başka çalışmada HBS sıklığı $\% 18,4$ olarak bildirilmiştir ${ }^{22}$. Bizim çalışmamızda da Minar ve arkadaşlarının çalışmasına benzer şekilde, üniversite öğrencileri arasında HBS sıklığ1 \% 7,6 olarak bulunmuștur; hafif ve orta düzey semptomlar öğrencilerin \%94,1'inde, şiddetli semptomlar ise sadece $\% 5,9$ 'nda mevcut olduğu gösterilmiştir ${ }^{20}$. HBS saptanan öğrencilerde daha önce HBS tanısının olmaması özellikle șiddet düzeyi hafif ve orta dereceli bireylerde ancak sorgulandığ1 zaman tespit edilebileceğini göstermektedir ${ }^{21}$.

Yapılan epidemiyolojik çalışmalarda HBS'de pozitif aile öyküsü \%40-60 oranında belirlenmiș olup, genetik geçiş çoğunlukla otozomal dominant olarak bilinmektedir. Ailesel olguların başlangıç yaşlarının daha erken olduğu ve daha şiddetli olarak ortaya çıktığ1 bildirilmiştir ${ }^{23}$. Bizim çalışmamızda da incelediğimiz bireylerin yaş ortalamaları dikkate alındığında, daha çok genetik etyolojinin geçerli olduğu yaş aralığında oldukları düşünülmektedir. Sonuçlarımıza göre, HBS saptadığımız bireylerin \%47,1'inde aile öyküsü mevcuttu ve ailevi özellikler barındıran bireylerin HBS şiddeti barındırmayanlara göre anlamlı olarak daha fazlaydı. Bu sonuç, çalışmaya katılan bireylerin önemli bir kısmında 
primer HBS varlığını düşündürse de, sekonder HBS nedenlerini dışlamak amacıyla herhangi bir tetkik yapılmadığı için kesin bir sonuca varmak mümkün değildir. Çalışmamızda, HBS kızlarda erkeklere göre daha yüksek saptanmasina rağmen bu farklılık istatistiksel olarak anlamlı bulunmamıştır. Sonuçlarımız, daha önceki çalışmaların sonuçları ile uyumlu olarak değerlendirilmiştir ${ }^{5,24}$.

HBS uyku, günlük aktiviteler, davranıș, bilișsel ve duygudurum üzerine olumsuz etkilere neden olan bir hastalıktır. Erişkinlerde HBS ile sağlık ilişkili yaşam kalitesi arasındaki ilişkiyi inceleyen az sayıda çalışma mevcuttur ${ }^{9,24-26}$. Abetz ve arkadaşları 85 HBS'li hasta ile genel toplumdan seçtikleri 2474 kişinin KF-36 puanlarını karşılaştırmışlardır. Sonuçlarında, HBS'li bireylerin fiziksel fonksiyon, fiziksel rol, emosyonel rol, sosyal fonksiyon, ağrı, genel sağlık, enerji ve mental sağlığı içeren ölçek puanlarının genel toplumdan daha düşük olduğunu ve artmış HBS şiddet düzeyinin fiziksel fonksiyon ve genel sağlık dışındaki tüm alanları önemli şekilde etkilediğini bildirmişlerdir ${ }^{25}$. Bir başka çalışmada, HBS bulunan bireylerin yaşam kalitesi, sağlıklı kontrollerin ve hipertansiyon, tip 2 diabet ve dizlerde osteoartrit gibi kronik hastalığa sahip bireylerin yaşam kalitesi ile karşılaștırılmış ve sadece osteoartriti bulunan hastalarin HBS bulunan bireylere göre daha kötü yaşam kalitesine sahip olduğu bulunmuştur ${ }^{27}$.

Silva ve arkadaşları adölesan ve genç erişkinlerde yaptıkları bir çalışmada HBS sıklığını \%8,4 olarak rapor etmişler ve HBS bulunan adölesan ve genç erişkinlerin daha kötü yaşam kalitesine sahip olduklarını, HBS semptomlarının yaşam kalitesi ile ilişkili olduğunu bildirmişlerdir ${ }^{24}$. Stevel ve arkadaşları 2112 kişiyle yaptıkları bir anket çalışmasında 107 kişinin HBS tanısı için gerekli 4 temel soruya 'evet' cevabı verdiğini ve HBS şiddetinin, özellikle HBS semptom sıklı̆̆ının KF-36 ölçeğinin bileșenlerinin çoğu ile negatif şekilde ilişkili olduğunu belirtmişlerdir ${ }^{26}$. Çalışmamızda da, bahsedilen çalışmaların sonuçlarına benzer olarak HBS bulunan bireylerde KF-36 ile ölçülen fiziksel ve mental yaşam kalitesi HBS bulunmayan bireylere göre daha kötüydü24-26. Ayrıca, HBS şiddet düzeyi ile KF-36 fiziksel bölümü skorları arasında anlamlı negatif ilişki saptandı.

Çalışmalar, HBS'nin uykuyu başlatmada zorluk, gün içerisinde artmış uykululuk, konsantrasyon ve öğrenme güçlüğü ile ilişkili olduğunu göstermişlerdir ${ }^{11,24}$. Picchietti ve arkadaşları, HBS tanısı olan adölesanların \%40'ının derslerine konsantre olamadığını ve HBS tanısı olan çocuk ve adölesanların \%48'inde ev veya okul başarısını etkileyen kognitif etkilenme olduğunu ve bu bireylerin \%45'inin konsantrasyon güçlüğü yaşadıklarını bildirmişlerdir ${ }^{11}$. Bu açıdan bakıldığında, çalışmamız üniversite öğrencilerinde HBS sıklığını ve yaşam kalitesi ile ilişkisini ortaya koyması bakımından önemlidir. Fakat çalıșmamızın kesitsel oluşu, tek merkez olması, sekonder HBS nedenlerini dışlamak amacıyla herhangi bir tetkik yapılmaması, HBS Şiddet Skalasının Türkçe geçerlik ve güvenirliğinin bulunmaması ve yaşam kalitesini etkileyebilecek diğer durumların değerlendirilmemesi kısıtlılıklar oluşturmaktadır.

Sonuç olarak, çalıșmamızda üniversite öğrencilerinde HBS sıklığ1 \% 7,6 olarak bulunmuş ve erişkinlerdeki görülme sılklığ1 ile benzer olduğu görülmüsstür. HBS bulunan ögrencilerde bulunmayanlara göre hem fiziksel hem de mental yaşam kalitesinin daha kötü olduğu bulunmuştur. Üniversite öğrencilerinin halen toplumda yeterince bilinmeyen ve yaşam kalitesini olumsuz etkileyebilen HBS açısından değerlendirilmesinin faydalı olacağını düşünmekteyiz.

\section{KAYNAKLAR}

1. Allen RA, Picchietti D, Hening WA, Trenkwalder C, Walters AS, Montplaisi J. Restless legs syndrome: diagnostic criteria, special considerations, and epidemiology. A report from the restless legs syndrome diagnosis an epidemiology workshop at the National Institutes of Health. Sleep Med. 2003;4:101-19.

2. Winkelman JW. Considering the causes of RLS. Eur J Neurol. 2006;13:8-14.

3. Bayard M, Avonda T, Wadzinski J. Restless legs syndrome. Am Fam Physician. 2008;78:235-40.

4. Yilmaz NH, Akbostanci MC, Oto A, Aykaç O. Prevalence of restless legs syndrome in Ankara, Turkey: an analysis of diagnostic criteria and awareness. Acta Neurol Belg. 2013;113:247-51.

5. Bjorvatn B, Leissner L, Ulfberg J, Gyring J, Karlsborg M, Regeur L et al. Prevalence, severity and risk factors of restless legs syndrome in the general adult population in two Scandinavian countries. Sleep Med. 2005;6:307-12.

6. Lavigne GJ, Montplaisir JY. Restless legs syndrome and sleep bruxism: prevalence and association among Canadians. Sleep. 1994;17:739-43.

7. Phillips B, Young T, Finn L, Asher K, Hening WA, Purvis C. Epidemiology of restless legs symptoms in adults. Arch Intern Med. 2000;160:2137-41. 
8. Phillips B, Hening W, Britz P, Mannino D. Prevalence and correlates of restless legs syndrome: results from the 2005 National Sleep Foundation Poll. Chest. 2006;129:76-80.

9. Allen RP, Walters AS, Montplaisir J Hening W, Myers A, Bell TJ et al. Restless legs syndrome prevalence and impact: REST general population study. Arch Intern Med. 2005;165:1286-92.

10. Hening W, Walters AS, Allen RP, Montplaisir J, Myers A, Ferini-Strambi L. Impact, diagnosis and treatment of restless legs syndrome (RLS) in a primary care population: the REST (RLS epidemiology, symptoms, and treatment) primary care study. Sleep Med. 2004;5:237-46.

11. Picchietti D, Allen RP, Walters AS, Davidson JE, Myers A, Ferini-Strambi L. Restless legs syndrome: prevalence and impact in children and adolescentsthe Peds REST study. Pediatrics. 2007;120:253-66.

12. Allen RP, Picchietti DL, Garcia-Borreguero D, Ondo WG, Walters AS, Winkelman JW et al. International Restless Legs Syndrome Study Group. Restless legs syndrome/Willis-Ekbom disease diagnostic criteria: updated International Restless Legs Syndrome Study Group (IRLSSG) consensus criteria--history, rationale, description, and significance. Sleep Med. 2014;15:860-73.

13. Allen RP, Stillman P, Myers AJ. Physician-diagnosed restless legs syndrome in a large sample of primary medical care patients in Western Europe: prevalence and characteristics. Sleep Med. 2010;11:31-7.

14. Walters AS, LeBrocq C, Dhar A, Hening W, Rosen $\mathrm{R}$, Allen RP et al. Validation of the International Restless Legs Syndrome Study Group rating scale for restless legs syndrome. Sleep Med. 2003;4:121-32.

15. Ware JE, Sherbourne CD. The MOS 36-item shortform health survey (SF-36). I. Conceptual framework and item selection. Med Care. 1992;30:473-83.

16. Carr AJ, Thompson PW, Kirwan JR. Quality of life measures. Br J Rheumatol. 1996;35:275-81.

17. Koçyiğit H, Aydemir Ö, Fişek G, Ölmez N, Memiş A. Kısa Form-36 (KF36)'nın Türkçe Versiyonunun güvenilirliği ve geçerliliği. İlaç ve Tedavi Dergisi.
1999;12:102-6

18. Sevim S, Doğu O, Camdeviren H, Bugdayc1 R, Sasmaz T, Kaleagası $\mathrm{H}$ et al. Unexpectedly low prevalence and unusual characteristics of RLS in Mersin, Turkey. Neurol. 2003;61:1562-9.

19. Erer S, Karli N, Zarifoglu M, Ozcakir A, Yildiz D. The prevalence and clinical features of restless legs syndrome: a door to door population study in Orhangazi, Bursa in Turkey. Neurol India. 2009;57:729-33.

20. Minár M, Valková P, Valkovič P. Prevalence and impact of restless legs syndrome in university students. Mov Disord. 2013;28:1157-8.

21. Yılmaz KO, Şadiye A, Bayram FB, Esenboğa T, Yapa AB, Coker B et al. Tip fakültesi ögrrencilerinde huzursuz bacak sendromu prevalansı. Parkinson Hastalıkları ve Hareket Bozuklukları Dergisi. 2009;12:13-7.

22. Özcan AT, Meral H, Özcan H. Ordu üniversitesi öğrencileri arasında huzursuz bacak sendromu sıklı̆̆1, özellikleri ve farkındalığı. Nöropsikiyatri Arşivi. 2013;50:175-9.

23. Allen RP, La Buda MC, Becker P, Earley CJ. Family history study of restless legs syndrome. Sleep Med. 2002;1:3-7.

24. Silva GE, Goodwin JL, Vana KD, Vasquez MM, Wilcox PG, Quan SF. Restless legs syndrome, sleep, and quality of life among adolescents and young adults. J Clin Sleep Med. 2014;10:779-86.

25. Abetz L, Allen R, Follet A, Washburn T, Earley C, Kirsch $\mathrm{J}$ et al. Evaluating the quality of life of patients with restless legs syndrome. Clin Ther. 2004;26:925-35.

26. Svetel MV, Jovic JS, Pekmezovic TD, Kostic VS. Quality of life in patients with primary restless leg syndrome: community-based study. Neurol Sci. 2015;36:1345-51.

27. Cho YW, Kim DH, Allen RP, Earley CJ. Assessing healthrelated quality of life in patients with restless legs syndrome in Korea: comparison with other chronic medical diseases. Sleep Med. 2012;13:115863. 